\title{
Garden varieties: How attractive are recommended garden plants to butterflies?
}

\author{
Kyle Shackleton $^{1} \cdot$ Francis L. W. Ratnieks ${ }^{1}$
}

Received: 30 June 2015/Accepted: 16 November 2015/Published online: 27 November 2015

(C) The Author(s) 2015. This article is published with open access at Springerlink.com

\begin{abstract}
One way the public can engage in insect conservation is through wildlife gardening, including the growing of insect-friendly flowers as sources of nectar. However, plant varieties differ in the types of insects they attract. To determine which garden plants attracted which butterflies, we counted butterflies nectaring on 11 varieties of summer-flowering garden plants in a rural garden in East Sussex, UK. These plants were all from a list of 100 varieties considered attractive to British butterflies, and included the five varieties specifically listed by the UK charity Butterfly Conservation as best for summer nectar. A total of 2659 flower visits from 14 butterfly and one moth species were observed. We performed a principal components analysis which showed contrasting patterns between the species attracted to Origanum vulgare and Buddleia davidii. The "butterfly bush" Buddleia attracted many nymphalines, such as the peacock, Inachis io, but very few satyrines such as the gatekeeper, Pyronia tithonus, which mostly visited Origanum. Eupatorium cannibinum had the highest Simpson's Diversity score of 0.75 , while Buddleia and Origanum were lower, scoring 0.66 and 0.50 respectively. No one plant was good at attracting all observed butterfly species, as each attracted only a subset of the butterfly community. We conclude that to create a butterfly-friendly garden, a variety of plant species are required
\end{abstract}

Electronic supplementary material The online version of this article (doi:10.1007/s10841-015-9827-9) contains supplementary material, which is available to authorized users.

Kyle Shackleton

K.Shackleton@Sussex.ac.uk

1 Laboratory of Apiculture and Social Insects (LASI), School of Life Sciences, University of Sussex, Brighton BN1 9QG, UK as nectar sources for butterflies. Furthermore, garden plant recommendations can probably benefit from being more precise as to the species of butterfly they attract.

Keywords Wildlife gardening · Butterfly $\cdot$ Insect conservation $\cdot$ Flowers $\cdot$ Nectar $\cdot$ Garden

\section{Introduction}

Butterflies are an important group of insects that can act as pollinators and environmental indicators but are facing widespread decline (Jennersten 1984; Thomas 2005, Polus et al. 2007; Thomas et al. 2011; Forister et al. 2010). Recent research has drawn attention to the resources butterflies use within their habitat (Dennis et al. 2006, Dennis 2010). One pivotal resource is floral nectar, which is the primary energy source for adults of most butterfly species and can enhance reproduction as nectar amino acids may compensate for a nutrient-poor larval diet (O'Brien et al. 2004; Mevi-Schütz and Erhardt 2005; Cahenzli and Erhardt 2013). Lack of an adequate nectar supply is potentially a limiting factor to butterfly populations and has been linked to population declines (Murphy et al. 1983; Wallisdevries and Swaay 2012; Curtis et al. 2015), although probably not all butterfly populations are nectar limited (Thomas et al. 2011).

Gardens normally contain ornamental flowers that can provide nectar and are increasingly being recognised for their value in supporting wildlife (McGeoch and Chown 1997; Gaston et al. 2007; Dearborn and Kark 2010). In the United Kingdom, a study in five major cities found that $99 \%$ of houses were associated with a garden and gardens covered at least $20 \%$ of the land area within those cities (Loram et al. 2007). Gardens have even been referred to as 
"England's most important nature reserve" (Owen and Owen 1975; Owen 2010). Many gardeners are environmentally conscious and seek to balance the aesthetic attributes of their garden with those that enhance its value to wildlife (Gaston et al. 2007; Freeman et al. 2012). This is termed "wildlife gardening" (Good 2000).

There is a huge variety of ornamental flowers available which differ in the number and diversity of insects they attract (Garbuzov and Ratnieks 2015; Garbuzov et al. 2015). With such choice, gardeners seeking advice as to which species to plant may turn to one of the many lists of "insect-friendly" garden flowers that are available. However, an analysis of 15 published lists found several shortcomings, including the fact that few were based on empirical data or gave any indication as to how they were constructed (Garbuzov and Ratnieks 2014a). Overall, there is a need for recommended lists of insect-friendly flowers to be put on a firmer scientific basis (Corbet et al. 2001; Garbuzov and Ratnieks 2014b).

For British butterflies, Vickery (1998) listed and ranked "the 100 best butterfly nectar plants in order of attraction". Five of these are featured on the Butterfly Conservation website (2014) as "the best plants for summer nectar". Vickery (1998) was the only list reviewed by Garbuzov and Ratnieks (2014a) which included information on its assembly. However, even this list provides little information on how its recommendations were derived, or which butterfly species are attracted to which plants. One of Butterfly Conservation's (2014) five plants is Buddleia davidii (Franch.), whose common name is the Butterfly Bush, implying that is attractive to butterflies in general. In this study, we surveyed butterflies on 11 varieties of ornamental flowers in a garden in East Sussex, UK, in late summer. All 11 were on the list of Vickery (1998), and included the five summer varieties recommended by Butterfly Conservation (2014). The aim was not to compare overall attractiveness to butterflies, but to determine differences among plant species in the butterfly species they attract.

\section{Methods}

\section{Study site and species}

The study was conducted in a rural garden in the village of Magham Down, East Sussex, England (decimal degrees $50.880426 \mathrm{~N}, 0.28488247 \mathrm{E})$. The garden included 11 flower varieties listed by Vickery (1998) including the five listed by Butterfly Conservation (2014) as best for summer nectar (Table 1). All plants were in good condition and in full view of the sun. All plants of a given species were of the same colour and variety.

\section{Butterfly sampling}

All data were collected between 09:00 and 18:00 in from 8 to 13 August 2013 during dry, sunny weather at temperatures of $17-25^{\circ} \mathrm{C}$ with zero or light wind when butterflies were most likely to be active. The survey was carried out during the period of the Big Butterfly Count, an annual citizen science and participation survey organized by Butterfly Conservation in the UK (Big Butterfly Count 2014). Each patch was visited three times per hour at intervals of $20 \mathrm{~min}$. A patch was defined as a discrete area of vegetation where only the focal plant was growing. The exception to this was Rubus fruticosus (bramble), which was growing in a hedge. During a visit, the observer identified and counted the number of each butterfly species foraging on a patch. The three counts from each hour were summed for statistical analysis to reduce zero-inflation. We made a total of 105 visits to each patch resulting in 35 data points $(105 / 3$ per hour $=35)$ for each plant. We emphasise that we counted the number of butterfly "feeding events" rather than the absolute number of butterflies. Thus, the data represent the flower choices made by the butterflies in the study garden.

\section{Statistical analysis}

We performed a principal components analysis (PCA) of the butterfly visits to characterise the structure of the butterfly community's choices of plant species. We used the prcomp function in $\mathrm{R}$ version 3.1.1 ( $\mathrm{R}$ Core Team 2014) to calculate a set of orthogonal standardised linear combinations (principal components) of the data (Crawley 2013). A scree plot was used to determine which principal components were most important in explaining the variation in the data. Additionally, we calculated Simpson's Diversity Index per plant variety, defined as $1-\sum_{i=1}^{S} \frac{n_{i}(n-1)}{N_{i}(N-1)}$ where $n$ is the number of visits of a particular butterfly species and $N$ is the total number of visits of all butterflies. We then compared the plant's rank (Vickery 1998, Table 1) with total butterfly diversity using Spearman's rank correlation coefficient.

\section{Results}

A total of 2659 Lepidoptera visits were recorded in the study, made by 14 butterfly and one moth species (see Supplementary Table A for a full summary). The recorded species are relatively common, and with the exception of Thymelicus sylvestris (Poda), all appear on the list of 19 common butterfly species and two moth species surveyed in the Big Butterfly Count (Big Butterfly Count 2014). A 
Table 1 List of plant species studied

\begin{tabular}{|c|c|c|c|c|c|}
\hline Species name & Common name & $\begin{array}{l}\text { Position in Vickery } \\
\text { (1998) }\end{array}$ & $\begin{array}{l}\text { Listed on Butterfly- } \\
\text { conservation.org? }\end{array}$ & $\begin{array}{l}\text { No. } \\
\text { patches }\end{array}$ & $\begin{array}{l}\text { Total area } \\
\mathrm{m}^{2}\end{array}$ \\
\hline Buddleia davidii (Franch.) & Buddleia & 1 & Yes & 4 & 5 \\
\hline Origanum vulgare (L.) & Marjoram & 5 & Yes & 3 & 15 \\
\hline $\begin{array}{l}\text { Lavendula angustifolia } \\
\text { (Mill.) }\end{array}$ & Lavender & 3 & Yes & 2 & 4 \\
\hline $\begin{array}{l}\text { Erysimum bicolor } \\
\text { (Hornem.) }\end{array}$ & $\begin{array}{l}\text { Perennial wallflower 'Bowles' } \\
\text { Mauve }\end{array}$ & 31 & Yes & 3 & 7.1 \\
\hline Verbena bonariensis (L.) & Vervain & 26 & Yes & 3 & 1.5 \\
\hline Eupatorium cannibinum (L.) & Hemp agrimony & $17^{\mathrm{a}}$ & No & 1 & 1 \\
\hline $\begin{array}{l}\text { Nepeta } x \text { faassenii } \\
\text { (Bergmans) }\end{array}$ & Catmint & 42 & No & 3 & 6 \\
\hline $\begin{array}{l}\text { Rubus fruticosus (Weihe and } \\
\text { Nees) }\end{array}$ & Bramble & 10 & No & 3 & 2 \\
\hline Lythrum salicaria $(\mathrm{L})$. & Purple loosestrife & 25 & No & 5 & 2.5 \\
\hline Lotus corniculatus (L.) & Bird's foot trefoil & 83 & No & 3 & 4.2 \\
\hline Dipsacus fullonum (L.) & Teasel & 55 & No & 4 & 2 \\
\hline
\end{tabular}

${ }^{a}$ In an apparent misprint, E. cannibinum is listed twice, in positions 17 and 96

few common species made up the vast majority of observations; Pyronia tithonus (L.) $37.2 \%$, Pieris rapae (L.) $19.8 \%$, Inachis io $12.3 \%$ and Maniola jurtina $11.0 \%$. Some species such as Lycaena phlaeas (L.) and Polyommatus icarus (Rottemburg) were less abundant, both making up less than $0.02 \%$ of individuals. Similarly, six of the plant species received over $95 \%$ of butterfly visits (Fig. 1). Origanum vulgare received $50.2 \%$ of all visits, mostly by $P$. tithonus, while $B$. davidii received $22.2 \%$ of visits. The poorest performing plant species was Lotus corniculatus which received only a single butterfly visit, from Maniola jurtina.

\section{Principal components analysis}

The scree plot (see Supplementary Material Figure A) indicated that the first two principal components (PCs) were far more important than subsequent PCs in explaining the structure of data: PC1 and PC2 explained 18.3 and $16.5 \%$ of the variation in the data respectively, compared to only $8.4 \%$ for PC3. We projected all butterfly species observation data onto the first two PCs to create a biplot (Fig. 2) which revealed two main clusters of points. The first cluster consists of several species with positive loadings on PC1 including M. jurtina and P. tithonus, indicating that PC1 correlates with a preference for Origanum. The second cluster consists of negative loadings on PC2 by species such as the I. io, Vanessa cardui (L.) and Vanessa atalanta (L.) indicating that PC2 correlates with a preference for Buddleia. However, since $P$. rapae had a strong influence on $\mathrm{PC} 1 \quad(26.8 \%$ of $P$. rapae present on
Origanum, $4.4 \%$ on Buddleia) and P. brassicae (L.) had a strong influence on PC2 (1.8\% on Origanum, $62.3 \%$ on Buddleia), PC1 and PC2 also correlate with "rarely visited Buddleia" and "rarely visited Origanum" respectively. In both cases, it appears that the most important factors of the PCA are associated with preferences for the two mostvisited plant species, Buddleia and Origanum.

\section{Ternary plot}

To present the feeding preferences of the different butterfly species with particular reference to Buddleia and Origanum, we created a ternary plot (Fig. 3). This enables three dimensions, the proportions of visits to Origanum, Buddleia, and the nine other plant species, to be plotted in a two-dimensional space. Each corner of the triangle represents exclusively visiting just one plant category. Each edge line represents the proportion of visits to the two plant categories at the two corners connected by the edge relative to each other, with the third plant category not being visited. Parameter space away from the edges means that all three plant categories are being visited. Several butterfly species are very close to either the Origanum corner (e.g. P. tithonus) or the Buddleia corner (e.g. I. io) of the triangle, meaning they almost exclusively visited Origanum and Buddleia, respectively. Conversely, some species are found close to the axis opposite to the Origanum corner (e.g. P. brassicae) or Buddleia corner (e.g. P. rapae) shown in purple and blue shading. This indicates a species which rarely visited Origanum or Buddleia respectively. A species near the centre of the plot, such as A. urticae, was 
Fig. 1 Proportions and numbers of butterfly visits to the six most visited plant species in Magham Down, East Sussex, August 2013.

A. $g=$ Autographa gamma,

A. $u=$ Aglais urticae,

C. $a=$ Celastrina argiolus,

I. $i=$ Inachis io,

L. $p=$ Lycaena phlaeas,

M. $j=$ Maniola jurtina,

P. $b=$ Pieris brassicae,

P. $c=$ Polygonia c-album,

P. $i=$ Polyommatus icarus,

P. $n=$ Pieris napi,

P. $r=$ Pieris rapae,

P. $t=$ Pyronia tithonus,

T. $s=$ Thymelicus sylvestris,

V. $a=$ Vanessa atalanta,

V. $c=$ Vanessa cardui
A 1

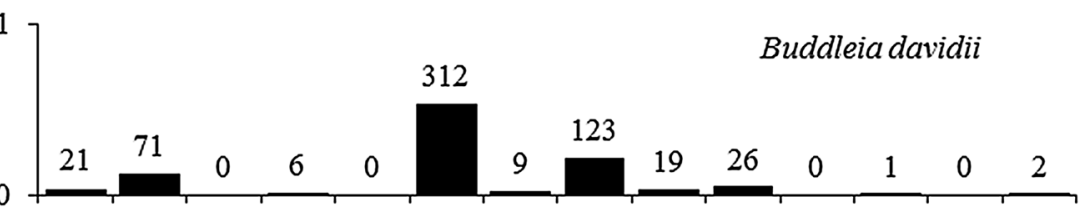

B 1
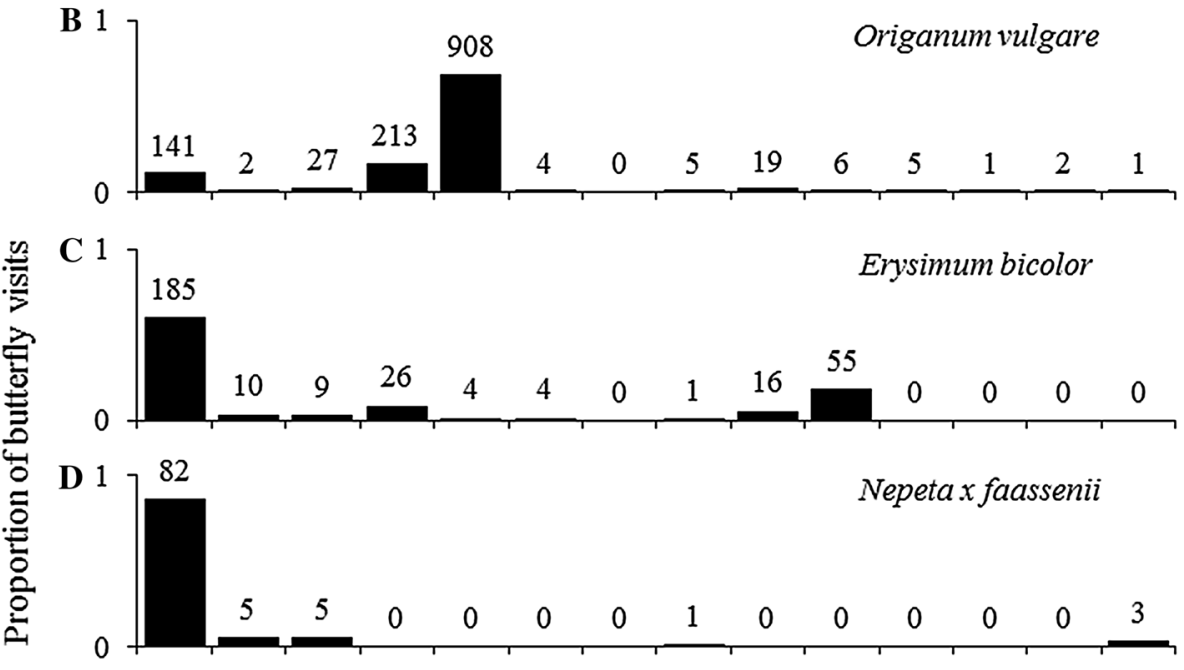

E 1
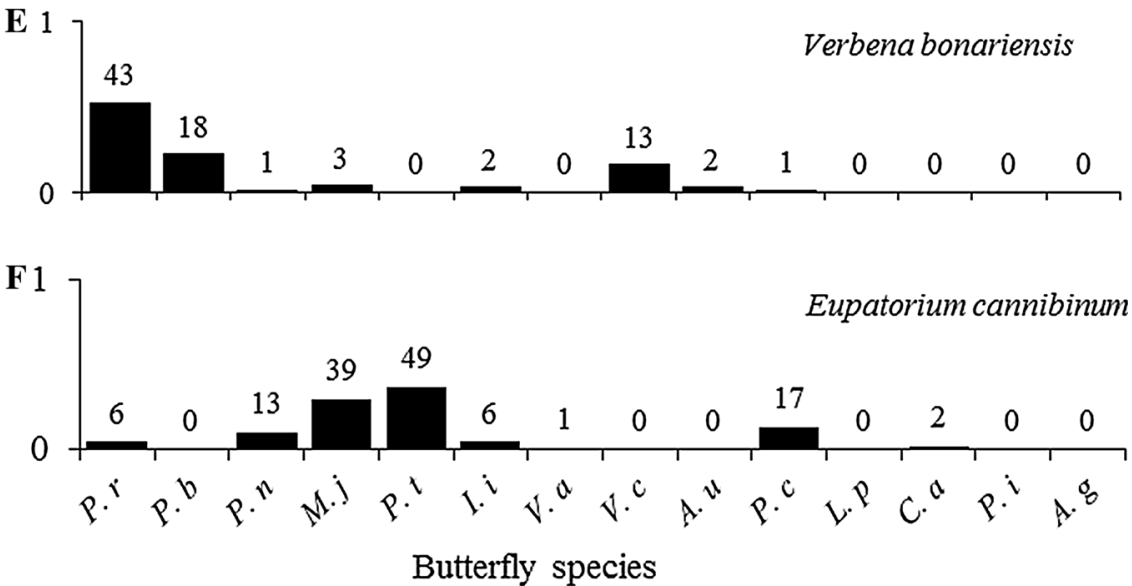

found almost equally on Origanum, Buddleia, and all other plants. We stress that this represents resource use among our study plants only, and that butterflies were free to forage on other resources in the landscape.

On the ternary plot, two subfamilies of the Nymphalidae, the Nymphalinae and the Satyrinae, formed separate clusters of points close to Buddleia and Origanum respectively. This mirrors the results of the principal components analysis. Maniola jurtina and Pyronia tithonus (Satyrinae) were very common on Origanum, while very few were observed on Buddleia or on other species (Fig. 3). Conversely, I. io, V. atalanta and V. cardui (Nymphalinae) had very high proportions of observations on Buddleia and very low proportions on Origanum. Aglais urticae was alone amongst the Nymphalidae in being counted a similar number of times on both buddleia and
Origanum. Interestingly, Pieris brassicae, the large white, showed markedly different feeding preferences to its congeners $P$. rapae and $P$. napi. The large white was observed mostly on Buddleia with few observations on Origanum. Conversely, $P$. rapae and $P$. napi had very few observations on Buddleia. All Pieridae, however, visited the other nine plant varieties more than either of the nymphalid subfamilies, indicating that they were more generalist in their feeding preferences.

\section{Correlation of plant rank butterfly diversity}

Plant rank in the list of Vickery (1998) was not significantly correlated with butterfly diversity $(P=0.595$, $\mathrm{R}=-0.182, \mathrm{n}=11$, Fig. 4$)$. Eupatorium cannibinum had the highest diversity of visiting butterflies, as it received a 


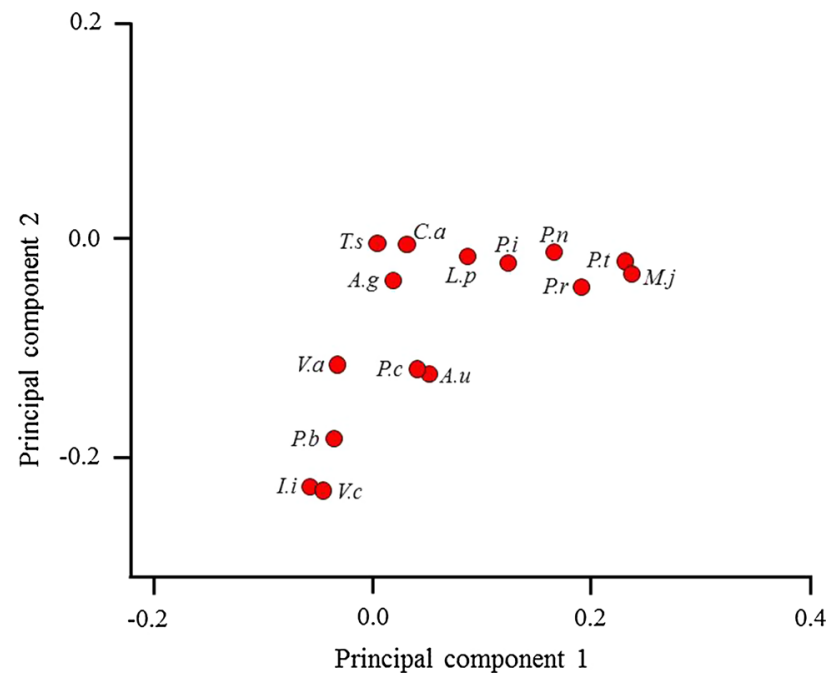

Fig. 2 Biplot of the first two principal components that explained 18.3 and $16.5 \%$ of the variation in the position of butterflies in "plant space". A. $g=$ Autographa gamma, A. $u=$ Aglais urticae, $C$. $a=$ Celastrina argiolus, $I . \quad i=$ Inachis io, $L . p=$ Lycaena phlaeas, M. $j=$ Maniola jurtina, $P . b=$ Pieris brassicae, $P$. $c=$ Polygonia $c$ album, $P . i=$ Polyommatus icarus, $P . n=$ Pieris napi, $P . r=$ Pieris rapae, $P . t=$ Pyronia tithonus, $T . \quad s=$ Thymelicus sylvestris, $V$. $a=$ Vanessa atalanta, $V . c=$ Vanessa cardui

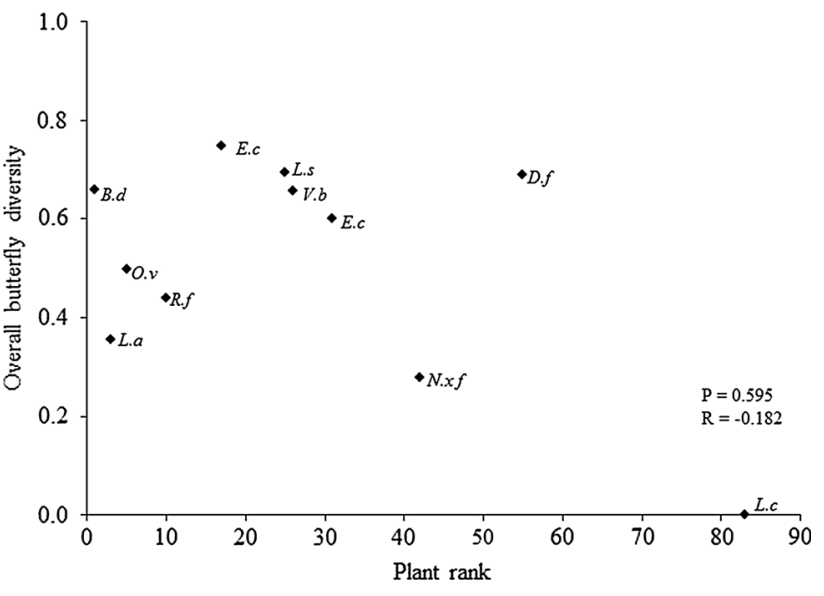

Fig. 4 Relationship between plant rank defined in Vickery (1998) with diversity calculated using Simpson's Diversity Index. $P$ and R-values calculated from Spearman's rank correlation coefficient. $B$. $d=$ Buddleia davidii, $D . f=$ Dipsacus fullonum, $E$. $b=$ Erysimum bicolor, E. $c=$ Eupatorium cannibinum, $L$. $a=$ Lavendula angustifolia, L. $c=$ Lotus corniculatus, L. $s=$ Lythrum salicaria, $N . x$ $f=$ Nepeta $x$ faassenii, $O . \quad v=$ Origanum vulgare, $R . f=$ Rubus fruticosus, $V . b=$ Verbena bonariensis

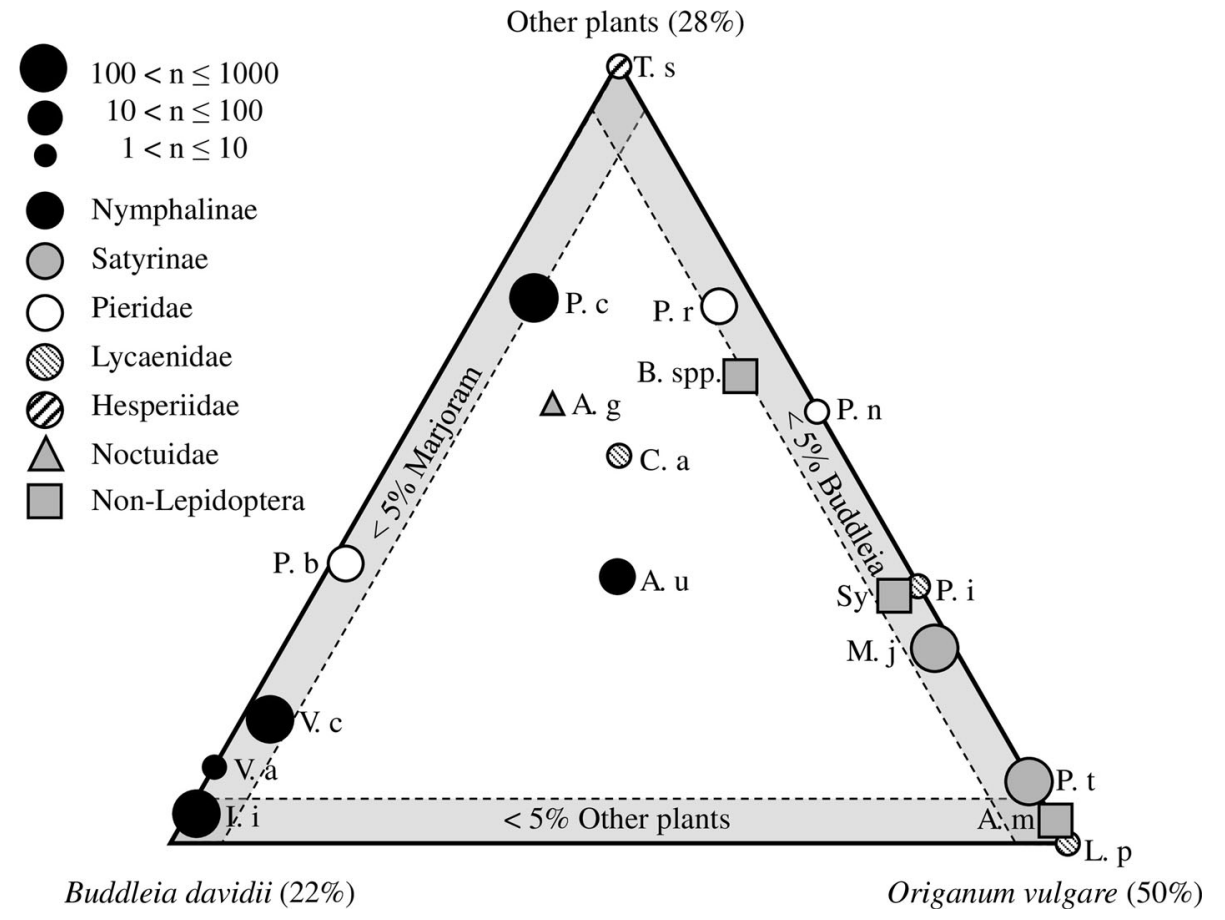

Fig. 3 The proportions of insects visiting Buddleia, Origanum, and the nine other plants combined. The position of a given species in the plot represents the proportion of counts on each of the three plant categories (Buddleia, Origanum, other). A species in a corner had $100 \%$ of its individuals recorded on that species, while a species close to an axis within a shaded area was rarely observed on the species opposite. A. $g=$ Autographa gamma, A. $u=$ Aglais urticae, C. $a=$ Celastrina argiolus, $I . \quad i=$ Inachis io, L. $p=$ Lycaena phlaeas, M. $j=$ Maniola jurtina, $P . \quad b=$ Pieris brassicae, $P$. $c=$ Polygonia c-album, $P . i=$ Polyommatus icarus, $P . n=$ Pieris napi, $P$. $r=$ Pieris rapae, $P$. $t=$ Pyronia tithonus, $T$. $s=$ Thymelicus sylvestris, $V . a=$ Vanessa atalanta, $V . c=$ Vanessa cardui 
more even proportion of its visits from satyrines, nymphalines and pierids than other plants. Lotus corniculatus was the poorest performing plant overall receiving only a sole butterfly visit, from $M$. jurtina, hence a diversity score of 0 .

\section{Discussion}

Our results show that butterfly species composition varied greatly among ornamental garden flowers. Each plant attracted only a subset of the butterfly community and no one plant was attractive to the majority of species. This was epitomised by $B$. davidii which was visited predominantly by nymphaline but not satyrine species, and $O$. vulgare which was visited predominantly by satyrine but not nymphaline species, with little overlap between the two plants. For example, the peacock butterfly, I. io (Nymphalinae), was far more frequently observed on Buddleia than Origanum (312 vs 4 visits). By contrast the gatekeeper, Pyronia tithonus (Satyrinae) was absent from Buddleia but extremely common on Origanum (0 vs 908 visits). Between them, Buddleia and Origanum received the majority of visits (1926 out of 2659). E. cannibinum however, had the highest diversity of butterfly visits as it attracted more even numbers of Pieridae and Nymphalinae. Plant rank (Vickery 1998) had no bearing on the diversity of visiting butterflies.

These results are broadly comparable to the data found in Peter Hardy's Butterfly Database (University of Staffordshire, accessed 09/09/2015) which contains over 13,000 butterfly feeding records. Considering visits to our 11 plant species, $81 \%$ of peacock butterflies were observed on Buddleia versus only $1.5 \%$ on Origanum. By contrast $15 \%$ of gatekeepers were observed on Buddleia ( $0 \%$ in the present study) but was still more common on Origanum (23\%) despite there being far more records made on Buddleia than Origanum in the database as a whole.

What causes the great disparity among plant species in the butterflies they attract? Corbet (2000) suggested that visitation to particular flower species was a combination of the nectar reward and the tongue length of the butterfly relative to the corolla length of the flower. That is, butterflies foraged on the most profitable flowers for which they could reach the nectar. However, this does completely explain the distribution of butterflies on the flowers we studied. For example, the small white has a tongue length exceeding the length of Buddleia corolla by almost $3 \mathrm{~mm}$ (Corbet 2000), but in our study relatively few small whites actually visited Buddleia.

One factor which could affect plant preference but is seldom noted is the strong possibility that butterflies have height preferences for feeding. Of our study plants, Buddleia was by far the tallest with most flowers being 1.5-3.0 $\mathrm{m}$ above ground. The next tallest were Verbena and Dipsacus at 1.5-2.0 $\mathrm{m}$ while most varieties had flowers at $<0.5 \mathrm{~m}$ above ground. Butterflies have other time constraints than foraging on the best nectar supply and may alter their foraging behaviour to increase access to mates or avoid predators. Because the Nymphalinae are conspicuous, there would be little value in attempting to hide from predators by staying low down, when better access to mates and flowers could be achieved by flying and foraging at a greater height. The less conspicuous Sayrinae, however, may be able to decrease their visibility by foraging on lowgrowing flowers amongst the denser vegetation. In particular, a butterfly species that was averse to foraging at heights of over c. $1.5 \mathrm{~m}$ would seldom be seen on Buddleia.

To enhance a garden's value as a nectar source for butterflies, our results indicate that planting multiple plant varieties which attract distinct subsets of the butterfly community would be beneficial. At its most basic this could be to plant both Buddleia and Origanum as both attracted many individuals and were attractive to different species. However, the butterflies observed in our study were all nectar generalists and common species, and included none of the 24 species under the UK Biodiversity Action Plan (BAP) (DEFRA 2007). This gives two possibilities for species that we did not observe. First, the local natal population was small or absent. Second, that our plants were not attractive to those species. As it is the rare and threatened species which tend to be specialist in their feeding preferences (Tudor et al. 2004, Hardy et al. 2007), ornamental flowers are likely to be of less value. For example, it would be unrealistic for gardeners to attempt to create the unique set of environmental conditions suitable for the large blue butterfly (Maculinea arion) (Thomas 1995). This puts limits on the ability of gardeners to conserve butterflies, but planting a selection of flowers will provide more forage than planting none at all.

Factors beyond attractiveness to butterflies must also be considered when considering the value of a particular plant as a nectar source. First, attractiveness to other insects as butterflies may make up only a small minority of flower visitors compared to bees and flies (Garbuzov and Ratnieks 2014b). Second, while non-native plants in general are not thought to be of great harm to the environment in Britain (Thomas and Palmer 2015), some species are problematic. Buddleia spreads rapidly, has the potential to usurp native species and is difficult and costly to remove (Tallent-Halsall and Watt 2009). Third, plants have a variable bloom period limiting the time available to insects as a food source. Dipsacus fullonum is a biennial which only blooms in August of its second year (Werner 1975). Even if $D$. 
fullonum is attractive for insects during this period, its overall value as a source of forage is low compared to varieties that bloom for many months such as Erysimum. Plants with long bloom periods are desirable, but bloom period can be extended through the use of "dead-heading" old inflorescences.

It is important for scientists investigating wildlife gardening disseminate their findings in order to assist the gardening public in encouraging wildlife. The use of citizen science is one possible route to achieving this, and much infrastructure is already in place. Butterfly Conservation's most recent survey, the Big Butterfly Count (2014), had over 44,000 participants who counted nearly 560,000 butterflies and moths. Surveys such as this, which generate large datasets, have the potential to empirically study the attractiveness of different plants to butterflies, while simultaneously engaging the public with wildlife gardening practices. Attracting butterflies to garden flowers can have further benefits to humans as contact with nature is thought to improve mental health and well-being (Burls and Caan 2005).

Our study was limited in scope given the time period over which it was conducted. Furthermore, the first two principal components explained $34.8 \%$ of the variation, a relatively low amount, suggesting resource use outside of our study plants. However, our results show clear patterns consistent with the existing data on butterfly nectar use. The short time span makes the data easier to interpret and removes interactions such as a plant which bloomed early being visited by a butterfly which is on the wing early. Further research is needed, both to bolster our conclusions with regards to butterfly nectaring and how gardens can provide other butterfly resources such as larval host plants and shelter. In particular, it is important to investigate the role gardens can play in helping rarer, more specialist butterflies.

No one plant was good at attracting all species of butterflies. Buddleia, the "butterfly bush", attracted mostly the large and brightly coloured nymphalines, but few other species. Would Buddleia have received its reputation and name if it attracted the same subset of brown satyrines which visit Origanum? To attract common species of butterflies, a vast variety of plants is probably not required. Rather, a few good varieties which collectively attract the majority of butterfly species. In Britain during summer, Buddleia, Origanum and Eupatorium would be a good start.

Acknowledgments KS's Ph.D. is funded by the National Environment Research Council (Grant Number: NE/K501347/1) and the School of Life Sciences, University of Sussex. We thank two referees for the constructive feedback.
Open Access This article is distributed under the terms of the Creative Commons Attribution 4.0 International License (http://crea tivecommons.org/licenses/by/4.0/), which permits unrestricted use, distribution, and reproduction in any medium, provided you give appropriate credit to the original author(s) and the source, provide a link to the Creative Commons license, and indicate if changes were made.

\section{References}

Big Butterfly Count (2014) Big Butterfly Count homepage http:// www.bigbutterflycount.org/. Accessed 02 Dec 2014

Burls A, Caan W (2005) Human health and nature conservation. $\mathrm{Br}$ Med J 331:1221-1222

Butterfly Conservation (2014) Butterfly Conservation Gardening http://butterfly-conservation.org/292/gardening.html. Accessed 02 Dec 2014

Cahenzli F, Erhardt A (2013) Nectar amino acids enhance reproduction in male butterflies. Oecologia 171:197-205

Corbet SA (2000) Butterfly nectaring flowers: butterfly morphology and flower form. Entomol Exp Appl 96:289-298

Corbet SA, Bee J, Dasmahapatra K, Gale S, Gorringe E, La Ferla B, Moorhouse T, Trevail A, van Bergen Y, Vorontsova M (2001) Native or exotic? Double or single? Evaluating plants for pollinator-friendly gardens. Ann Bot Lond 87:219-232

Crawley MJ (2013) The R book, 2nd edn. Wiley, Hoboken

Curtis RJ, Brereton TM, Dennis RLH, Carbone C, Isaac NJB (2015). Butterfly abundance is determined by food availability and is mediated by species traits. J Appl Ecol

Dearborn DC, Kark S (2010) Motivations for conserving urban biodiversity. Conserv Biol 24:432-440

DEFRA (2007) UK BAP priority terrestrial invertebrate species http://jncc.defra.gov.uk/page-5169. Accessed 01 May 2015

Dennis RLH (2010) A Resource-based habitat view for conservation. Butterflies in the British landscape. Wiley-Blackwell, Chichester, UK

Dennis RLH, Shreeve TG, Dyck HV (2006) Habitats and resources: the need for a resource-based definition to conserve butterflies. Biodivers Conserv 15:1943-1966

Forister ML, McCall AC, Sanders NJ, Fordyce JA, Thorne JH, O'Brien J, Waetjen DP, Shapiro AM (2010) Compounded effects of climate change and habitat alteration shift patterns of butterfly diversity. Proc Natl Acad Sci USA 107:2088-2092

Freeman C, Dickinson KJM, Porter S, van Heezik Y (2012) "My garden is an expression of me": exploring householders' relationships with their gardens. J Environ Psychol 32:135-143

Garbuzov M, Ratnieks FLW (2014a) Listmania: the strengths and weaknesses of lists of garden plants to help pollinators. BioScience biu 150

Garbuzov M, Ratnieks FLW (2014b) Quantifying variation among garden plants in attractiveness to bees and other flower-visiting insects. Funct Ecol 28:364-374

Garbuzov M, Ratnieks FLW (2015) Using the British national collection of asters to compare the attractiveness of 228 varieties to flower-visiting insects. Environ Entomol nvv037

Garbuzov M, Samuelson EEW, Ratnieks FLW (2015) Survey of insect visitation of ornamental flowers in Southover Grange garden, Lewes, UK. Insect Sci 22:700-705

Gaston KJ, Fuller RA, Loram A, MacDonald C, Power S, Dempsey N (2007) Urban domestic gardens (XI): variation in urban wildlife gardening in the United Kingdom. Biodivers Conserv 16:3227-3238 
Good R (2000) The value of gardening for wildlife-What contribution does it make to conservation? Br Wildl 12:77-84

Hardy PB, Sparks TH, Isaac NJB, Dennis RLH (2007) Specialism for larval and adult consumer resources among British butterflies: implications for conservation. Biol Conserv 138:440-452

Jennersten O (1984) Flower visitation and pollination efficiency of some North European butterflies. Oecologia 63:80-89

Loram A, Tratalos J, Warren PH, Gaston KJ (2007) Urban domestic gardens $(\mathrm{X})$ : the extent and structure of the resource in five major cities. Landsc Ecol 22:601-615

McGeoch MA, Chown SL (1997) Impact of urbanization on a gallinhabiting Lepidoptera assemblage: the importance of reserves in urban areas. Biodivers Conserv 6:979-993

Mevi-Schütz J, Erhardt A (2005) Amino acids in nectar enhance butterfly fecundity: a long-awaited link. Am Nat 165:411-419

Murphy DD, Launer AE, Ehrlich P (1983) The role of adult feeding in egg production and population dynamics of the checkerspot butterfly Euphydryas editha. Oecologia 56:257-263

O'Brien DM, Boggs CL, Fogel ML (2004) Making eggs from nectar: the role of life history and dietary carbon turnover in butterfly reproductive resource allocation. Oikos 105:279-291

Owen J (2010) Wildlife of a garden. A thirty-year study. Royal Horticultural Society, Peterborough

Owen J, Owen DF (1975) Suburban gardens: England's most important nature reserve? Environ Conserv 2:53-59

Peter Hardy's Butterfly Database, University of Staffordshire, http:// www.staffs.ac.uk/schools/sciences/geography/links/IESR/down loads/nectaring.xls. Accessed 09 Sept 2015

Polus E, Vandewoestijne S, Choutt J, Baguette M (2007) Tracking the effects of one century of habitat loss and fragmentation on calcareous grassland butterfly communities. Biodivers Conserv $16: 3423-3436$

R Core Team (2014) R: A language and environment for statistical computing. R Foundation for Statistical Computing, Vienna, Austria. URL http://www.R-project.org/

Tallent-Halsell NG, Watt MS (2009) The invasive Buddleja davidii (butterfly bush). Bot Rev 75:292-325

Thomas JA (1995) The ecology and conservation of Maculinea arion and other European species of large blue butterfly. In: Pullin AS (ed) Ecology and conservation of butterflies, Springer, Netherlands. pp 180-197

Thomas JA (2005) Monitoring change in the abundance and distribution of insects using butterflies and other indicator groups. Philos Trans R Soc B 360:339-357

Thomas CD, Palmer G (2015) Non-native plants add to the British flora without negative consequences for native diversity. Proc Natl Acad Sci USA 112:4387-4392

Thomas JA, Simcox DJ, Hovestadt T (2011) Evidence based conservation of butterflies. J Insect Conserv 15:241-258

Tudor O, Dennis RLH, Greatorex-Davies JN, Sparks TH (2004) Flower preferences of woodland butterflies in the UK: nectaring specialists are species of conservation concern. Biol Conserv 119:397-403

Vickery ML (1998) Gardening for butterflies. British Butterfly Conservation Society, Dorset

Wallisdevries MF, Swaay CAMV (2012) Changes in nectar supply: a possible cause of widespread butterfly decline. Curr Zool 20:384-391

Werner PA (1975) Predictions of fate from rosette size in teasel (Dipsacus fullonum). Oecologia 20:197-201 